\title{
Fixação biológica de nitrogênio em cultivares de feijão-caupi recomendadas para o Estado de Roraima
}

\author{
Shirlany Ribeiro de Melo(1) e Jerri Édson Zilli(2) \\ (1)Universidade Federal de Roraima, Centro de Ciências Agrárias, Campus do Cauamé, Rodovia BR 174, Km 12, CEP 69310-270 Boa Vista, RR. \\ E-mail: shirlanymelo@hotmail.com ${ }^{(2)}$ Embrapa Roraima, Rodovia BR 174, Km 08, Distrito Industrial, Caixa Postal 133, CEP 69301-970 Boa \\ Vista, RR. E-mail: zilli@cpafrr.embrapa.br
}

\begin{abstract}
Resumo - O objetivo deste trabalho foi avaliar a fixação biológica de nitrogênio (FBN) em cinco cultivares de feijão-caupi: BR 17 Gurguéia, BRS Guariba, BRS Mazagão, UFRR Grão Verde e Pretinho Precoce 1. Em 2007, foram conduzidos um experimento em casa de vegetação e outro em campo, em esquema fatorial com cinco cultivares de feijão-caupi e quatro fontes de nitrogênio: adubação com ureia $\left(50 \mathrm{~kg} \mathrm{ha}^{-1} \mathrm{de} \mathrm{N}\right)$, inoculação com a estirpe de Bradyrhizobium BR 3262 ou BR 3267 e um controle absoluto. Aos 35 dias após a emergência das plantas, foram avaliados número e massa de nódulos secos, massa de matéria seca e $\mathrm{N}$ total da parte aérea, eficiência nodular em casa de vegetação e rendimento de grãos na colheita em campo. Em casa de vegetação, foi observada alta nodulação e eficiência nodular para ambas as estirpes em todas as cultivares. Em campo, a nodulação e o $\mathrm{N}$ total foram menores para todas as cultivares, comparativamente à casa de vegetação, o que indica interferência de fatores edafoclimáticos na FBN. Ocorreu aumento no rendimento de grãos em todas as cultivares em decorrência da inoculação, especialmente com a estirpe BR 3262.
\end{abstract}

Termos para indexação: Bradyrhizobium, Vigna unguiculata, fixação biológica de nitrogênio.

\section{Biological nitrogen fixation in cowpea cultivars recommended for Roraima state, Brazil}

\begin{abstract}
The objective of this work was to evaluate the biological nitrogen fixation (BNF) in five cowpea cultivars: BR 17 Gurguéia, BRS Guariba, BRS Mazagão, UFRR Grão Verde and Pretinho Precoce 1. In 2007, one greenhouse and one field experiment were performed using a factorial design with five cowpea cultivars and four nitrogen sources: urea fertilization ( $50 \mathrm{~kg} \mathrm{ha}^{-1}$ of N), inoculation with BR 3262 or BR 3267 Bradyrhizobium strains, and absolute control. Thirty-five days after plant emergency, the number and dry weight of nodules, the dry matter weight and the total $\mathrm{N}$ of the shoots, the nodule efficiency in greenhouse plants and the grain yield for the field experiment plants were evaluated. In the greenhouse, high nodulation and nodule efficiency were observed for both strains in all cultivars. In the field, the nodulation and total $\mathrm{N}$ were lower for all cultivars in comparison with the greenhouse experiment, which indicates the interference of edaphoclimatic factors in the BNF. An increase in grain yield was observed for all cultivars as a consequence of the inoculation, especially for the BR 3262 strain.
\end{abstract}

Index terms: Bradyrhizobium, Vigna unguiculata, biological nitrogen fixation.

\section{Introdução}

A utilização de insumos biológicos em substituição aos insumos químicos industrializados tem sido cada vez mais frequente na agricultura. E a fixação biológica de nitrogênio (FBN) tem se mostrado indispensável para a sustentabilidade da agricultura brasileira, haja vista o fornecimento de nitrogênio às culturas com baixo custo econômico e impacto ambiental reduzido (Hungria et al., 2007).

Para a cultura do feijão-caupi [Vigna unguiculata (L.) Walp.], estima-se uma área plantada de 150 mil hectares na Região Amazônica, e pesquisas têm mostrado resultados positivos para o aumento da produtividade de grãos com a inoculação de bactérias do gênero Bradyrhizobium nas sementes (Martins et al., 2003; Lacerda et al., 2004; Soares et al., 2006; Zilli et al., 2006, 2008). Nesses trabalhos, foi demonstrado que a inoculação de estirpes bacterianas eficientes é capaz de substituir a adubação nitrogenada de até $80 \mathrm{~kg} \mathrm{ha}^{-1}$, na forma de ureia, e aumentar o rendimento de grãos do feijão-caupi em mais de $30 \%$.

$\mathrm{O}$ uso de inoculantes com bactérias eficientes na FBN em condições de campo tem se mostrado uma 
estratégia importante para o aumento da produtividade do feijão-caupi, e quatro estirpes de Bradyrhizobium são atualmente recomendadas para esta cultura: UFLA3-84 (SEMIA 6461), BR 3267 (SEMIA 6462), INPA3-11B (SEMIA 6463) e BR 3262 (SEMIA 6464) (Zilli et al., 2008).

Contudo, embora a cultura apresente ampla capacidade na FBN, nem sempre são observadas respostas positivas do uso de inoculantes em campo, em razão de o feijão-caupi ser cultivado, na maioria das vezes, em condições de subsistência com baixo aporte tecnológico e apresentar baixa especificidade na nodulação (Zilli et al., 2008). O feijão-caupi é capaz de nodular e estabelecer simbiose com diversas espécies de bactérias do grupo rizóbio, incluídos os gêneros Azorhizobium, Burkholderia, Bradyrhizobium, Mesorhizobium, Rhizobium, Sinorhizobium, entre outros (Neves \& Rumjanek, 1997; Willems, 2006; Zilli et al., 2006; Zhang et al., 2007; Moreira, 2008). Esta baixa especificidade da cultura em relação ao microssimbionte mostra-se limitante à exploração tecnológica da FBN, uma vezque as bactérias nodulantes estabelecidas no solo, além de ser competitivas e estar em número elevado, apresentam eficiência variável na FBN (Thies et al., 1991; Hara \& Oliveira, 2007).

Além das peculiaridades inerentes ao microssimbionte, também há relatos de que determinados genótipos de feijão-caupi apresentam maior capacidade de nodulação e eficiência na FBN, o que indica a possibilidade de otimização das respostas quanto à FBN com o uso de cultivares eficientes, ou mesmo com a implementação de programas de melhoramento vegetal para a FBN (Sanginga et al., 2000; Fall et al., 2003; Xavier et al., 2006).

O objetivo deste trabalho foi avaliar a FBN em cinco cultivares de feijão-caupi recomendadas para o Estado de Roraima (BR 17 Gurguéia, BRS Guariba e BRS Mazagão) ou em fase de recomendação (UFRR Grão Verde e Pretinho Precoce 1).

\section{Material e Métodos}

Entre os meses de março e abril de 2007, um experimento foi conduzido em condições controladas em casa de vegetação na Embrapa Roraima, Boa Vista, RR. O delineamento foi em blocos ao acaso com três repetições e esquema fatorial $5 \times 4$ : cinco cultivares de feijão-caupi e quatro fontes de nitrogênio
- duas estirpes de Bradyrhizobium, um controle sem inoculação e sem $\mathrm{N}$ e um tratamento com $40 \mathrm{mg}$ de N por vaso por semana, na forma de nitrato de amônio, correspondente a uma adubação de $50 \mathrm{~kg} \mathrm{ha}^{-1}$ de N. As cultivares de feijão-caupi utilizadas foram BR 17 Gurguéia, BRS Guariba, BRS Mazagão, Pretinho Precoce 1 e UFRR Grão Verde; e as estirpes de Bradyrhizobium, BR 3267 (SEMIA 6462) e BR 3262 (SEMIA 6464).

As sementes do feijão-caupi foram previamente desinfestadas (30 s em etanol $70 \%, 5 \mathrm{~min}$ em hipoclorito de sódio 5\%, dez lavagens sucessivas com água destilada e autoclavada), e semeadas (quatro sementes por vaso, deixando-se apenas uma planta após o desbaste) em vasos de Leonard (Vicent, 1970) com substrato areia:vermiculita $(2: 1 ; \mathrm{v}: \mathrm{v})$ esterilizado em autoclave $\left(121^{\circ} \mathrm{C} ; 90 \mathrm{~min} ; 1 \mathrm{~atm}\right)$. Semanalmente, os vasos receberam 0,3 L de solução nutritiva de Norris (Norris \& Date, 1976) e irrigação com água destilada autoclavada quando necessário.

Os inoculantes foram preparados por meio do cultivo das estirpes bacterianas em meio de cultura YM (Fred \& Waksman, 1928), seguido de incubação por cerca de 96 horas a $28^{\circ} \mathrm{C}$. Após esse período, as bactérias foram inoculadas nas plântulas três dias após a semeadura, com a aplicação do inoculante (1 mL por plântula), que continha aproximadamente 600 mil unidades formadoras de colônias (UFC).

Aos 35 dias após a emergência, as plantas do feijão-caupi foram coletadas e as raízes foram separadas da parte aérea na altura do nó cotiledonar. Os nódulos foram destacados das raízes, lavados e contados. Posteriormente, nódulos e parte aérea foram secos em estufa $\left(60^{\circ} \mathrm{C}\right.$ por 72 horas) para determinação da massa de matéria seca. Após a pesagem, a parte aérea das plantas foi moída para a determinação do $\mathrm{N}$ total pelo método de Kjeldahl (Liao, 1981). As variáveis analisadas foram: número e massa de nódulos secos, massa da matéria seca e $\mathrm{N}$ total da parte aérea e eficiência nodular ( $\mathrm{N}$ total da parte aérea por massa de nódulos secos de cada planta).

Entre os meses de agosto e setembro de 2007, foi conduzido um experimento no campo experimental Água Boa, da Embrapa Roraima (60³9'54"W, $02^{\circ} 15^{\prime} 00^{\prime \prime} \mathrm{N}$, aproximadamente $90 \mathrm{~m}$ de altitude), em área representativa do cerrado de Roraima.

O solo, em área de primeiro cultivo, foi preparado com antecedência de seis meses, com incorporação 
da vegetação nativa por meio de utilização de grade aradora e com aplicação de $1.500 \mathrm{~kg} \mathrm{ha}^{-1}$ de calcário dolomítico (PRNT 80-85\%), $100 \mathrm{~kg} \mathrm{ha}^{-1}$ de $\mathrm{P}_{2} \mathrm{O}_{5}$ na forma de superfosfato simples e $50 \mathrm{~kg} \mathrm{ha}^{-1} \mathrm{de}$ FTE BR-12. Posteriormente, foi semeado milheto, o qual foi dessecado com glifosato na dose recomendada dez dias antes da semeadura do feijão-caupi.

A análise de solo (Claessen, 1997), realizada antes da implantação do experimento na profundidade de 0 a $20 \mathrm{~cm}$ em uma amostra composta por dez amostras simples, mostrou as seguintes características: $\mathrm{pH}$ em $\mathrm{CaCl}_{2}, 5,2$; alumínio, $0,00 \mathrm{cmol}_{\mathrm{c}} \mathrm{dm}^{-3}$; potássio, $0,04 \mathrm{cmol}_{\mathrm{c}} \mathrm{dm}^{-3}$; cálcio, $1,01 \mathrm{cmol}_{\mathrm{c}} \mathrm{dm}^{-3}$; magnésio, $0,30 \mathrm{cmol}_{\mathrm{c}} \mathrm{dm}^{-3}$; matéria orgânica, $10,03 \mathrm{~g} \mathrm{dm}^{-3}$; fósforo, 30,01 $\mathrm{mg} \mathrm{dm}^{-3}$; número de células de rizóbio nodulantes do feijão-caupi, determinado pelo método de infecção em plantas (Campo \& Hungria, 2007), 1,9x10 UFC g $^{-1}$ de solo e textura: $870 \mathrm{~g} \mathrm{~kg}^{-1}$ de areia, $120 \mathrm{~g} \mathrm{~kg}^{-1}$ de argila e $10 \mathrm{~g} \mathrm{~kg}^{-1}$ de silte.

Como adubação de plantio, foram distribuídos mecanicamente na linha de plantio $80 \mathrm{~kg} \mathrm{ha}^{-1}$ de $\mathrm{P}_{2} \mathrm{O}_{5}$ na forma de superfosfato simples e $60 \mathrm{~kg} \mathrm{ha}^{-1}$ de $\mathrm{K}_{2} \mathrm{O}$ na forma de cloreto de potássio (50\% no plantio e 50\% 30 dias após a emergência das plantas).

$\mathrm{O}$ experimento foi conduzido em blocos ao acaso com quatro repetições (parcelas de 5x4 m) e esquema fatorial com cinco cultivares de feijão-caupi e quatro fontes de nitrogênio: duas estirpes de Bradyrhizobium, um tratamento com $50 \mathrm{~kg} \mathrm{ha}^{-1}$ de $\mathrm{N}$ aplicados no plantio, na forma de ureia, e um controle sem inoculação e sem nitrogênio. As cultivares de feijão-caupi e as estirpes de Bradyrhizobium utilizadas foram as mesmas do experimento realizado em condições controladas.
A semeadura do feijão-caupi consistiu na distribuição manual das sementes no espaçamento de $0,50 \mathrm{~m}$ entre linhas e 8-10 sementes por metro linear, enquanto a inoculação foi realizada por meio da aplicação de uma dose de 600 mil UFC por semente (volume de líquido de $3 \mathrm{~mL} \mathrm{~kg}^{-1}$ de sementes), por meio de inoculante produzido da forma descrita para o experimento anterior.

As variáveis avaliadas nesse experimento foram: número e massa de nódulos secos, massa da matéria seca e $\mathrm{N}$ total da parte aérea, e rendimento de grãos (umidade de 13\%) na colheita. A amostragem para avaliação da nodulação e parte aérea foi realizada 35 dias após a emergência das plantas, com a coleta de dez plantas na segunda linha de plantio em cada parcela. Para a avaliação do rendimento de grãos, foi realizada colheita em uma área útil de $6 \mathrm{~m}^{2}$ nas quatro linhas centrais em cada parcela.

Os dados obtidos foram submetidos à análise de variância com o teste $\mathrm{F}$ a $5 \%$ de probabilidade, de acordo com o delineamento de cada experimento, e ao teste de Tukey, a 5\% de probabilidade. Os dados de número e massa de nódulos foram transformados para raiz quadrada.

\section{Resultados e Discussão}

Nos tratamentos que não receberam inoculação (controle sem inoculação e sem nitrogênio, e nitrogenado), praticamente não houve formação de nódulos nas plantas (Tabela 1), o que mostra ter havido baixa contaminação com bactérias entre os tratamentos. No campo, esses tratamentos apresentaram considerável

Tabela 1. Número e massa de nódulos secos de plantas de feijão-caupi em casa de vegetação e em campo, em Roraima ${ }^{(1)}$.

\begin{tabular}{|c|c|c|c|c|}
\hline \multirow[t]{2}{*}{ Tratamento } & \multicolumn{2}{|c|}{ № de nódulos por planta } & \multicolumn{2}{|c|}{ Massa de nódulos secos (mg por planta) } \\
\hline & Casa de vegetação & Campo & Casa de vegetação & Campo \\
\hline & \multicolumn{4}{|c|}{ Fontes de nitrogênio } \\
\hline Controle & $1,2 \mathrm{bC}$ & $13,3 \mathrm{aB}$ & $3,2 \mathrm{bB}$ & $137,4 \mathrm{aBC}$ \\
\hline Nitrogenado & $1,5 \mathrm{aC}$ & $9,9 \mathrm{aB}$ & $3,8 \mathrm{bB}$ & $90,4 \mathrm{aC}$ \\
\hline BR 3267 & $264,1 \mathrm{aA}$ & $21,0 \mathrm{bA}$ & $402,0 \mathrm{aA}$ & $168,7 \mathrm{bAB}$ \\
\hline BR 3262 & $141,6 \mathrm{aB}$ & $24,6 \mathrm{bA}$ & $343,4 \mathrm{aA}$ & $216,1 \mathrm{bA}$ \\
\hline \multicolumn{5}{|c|}{ Cultivares } \\
\hline BR 17 Gurguéia & $97,8 \mathrm{aA}$ & $16,6 \mathrm{bAB}$ & $214,8 \mathrm{aA}$ & $125,0 \mathrm{bA}$ \\
\hline UFRR Grão Verde & $66,1 \mathrm{aAB}$ & $19,5 \mathrm{bA}$ & $193,8 \mathrm{aA}$ & $155,5 \mathrm{aA}$ \\
\hline BRS Mazagão & $61,3 \mathrm{aAB}$ & $17,1 \mathrm{bAB}$ & $246,3 \mathrm{aA}$ & $156,3 \mathrm{bA}$ \\
\hline BRS Guariba & $45,7 \mathrm{aAB}$ & $20,5 \mathrm{bA}$ & $192,8 \mathrm{aA}$ & $174,2 \mathrm{aA}$ \\
\hline Pretinho Precoce 1 & $42,5 \mathrm{aB}$ & $10,8 \mathrm{bB}$ & $202,9 \mathrm{aA}$ & $132,7 \mathrm{bA}$ \\
\hline CV (\%) & \multicolumn{2}{|c|}{34,35} & \multicolumn{2}{|c|}{32,76} \\
\hline
\end{tabular}

${ }^{(1)}$ Médias seguidas de letras iguais, minúsculas nas linhas em uma mesma variável, e maiúsculas nas colunas, dentro de fontes de nitrogênio ou cultivares, não diferem entre si pelo teste de Tukey, a $5 \%$ de probabilidade. 
nodulação em consequência da alta população de bactérias nodulantes estabelecida no solo. Em casa de vegetação, foi observado maior número médio de nódulos nas plantas do tratamento com inóculo da estirpe BR 3267; no campo os tratamentos com inóculo apresentaram número de nódulos iguais entre si e maiores que os demais tratamentos, os quais também não apresentaram diferenças entre si, apenas a estirpe BR 3262 apresentou número de nódulos superior ao tratamento com $\mathrm{N}$, enquanto os demais tratamentos não diferiram. Quanto à massa de nódulos, não houve diferença entre os tratamentos com as duas estirpes em casa de vegetação. No campo, contudo, a estirpe BR 3262 proporcionou massa de nódulos superior à do controle e, embora BR 3267 não tenha diferido de BR 3262, foi superior apenas ao tratamento nitrogenado.

O fato de o tratamento controle ter apresentado nodulação expressiva no campo (Tabela 1) é uma indicação da alta capacidade dos rizóbios estabelecidos no solo nodularem as plantas de feijão-caupi, como é frequentemente observado (Rumjanek et al., 2005; Hara \& Oliveira, 2007; Zhang et al., 2007). Entretanto, a tendência de menor nodulação obtida no tratamento com $\mathrm{N}$ em relação ao controle mostra que esse nutriente aplicado no plantio restringiu a nodulação espontânea, fato também observado em outros trabalhos (Salvagiotii et al., 2008).

Com relação às estirpes, os resultados de nodulação mostraram que ambas possuem capacidade de nodulação as cultivares de feijão-caupi avaliadas, pois formaram mais de cem nódulos por planta em casa de vegetação, o que corrobora observações anteriores (Martins et al., 2003; Zilli et al., 2006). No entanto, o menor número de nódulos obtido em condições de campo, especialmente com a estirpe BR 3267 - cerca de 21 nódulos por planta na média geral - além da menor massa de nódulos, significa uma limitação à nodulação das plantas nesse ambiente, mesmo com inoculação. Tal limitação pode estar associada a fatores edáficos, especialmente aos baixos teores de $\mathrm{Ca}$ e $\mathrm{Mg}$ observados, ou à grande quantidade de rizóbios nodulantes de feijão-caupi presentes no solo (cerca de $1.900 \mathrm{UFC} \mathrm{g}^{-1}$ de solo), que teria competido com as estirpes utilizadas para inoculação ou, ainda, dificultado a sobrevivência das estirpes inoculantes no campo (Delavechia et al., 2003; Watkin et al., 2003).

Foram observadas diferenças significativas no número de nódulos (Tabela 1) entre as cultivares de feijão-caupi em casa de vegetação. A cultivar BR 17 Gurguéia formou pelo menos $30 \%$ mais nódulos comparativamente às outras cultivares e mais de $100 \%$ em relação a Pretinho
Precoce 1, que formou o menor número de nódulos em ambos os ambientes. De fato, em casa de vegetação, todas as cultivares apresentaram boa nodulação (acima de 40 nódulos por planta), embora não tenha havido diferença na massa de nódulos. Em condições de campo, por outro lado, todas as cultivares formaram menor número de nódulos em comparação com a casa de vegetação, e as cultivares BR 17 Gurguéia, BRS Mazagão e Pretinho Precoce 1 também tiveram menor massa de nódulos em condições de campo, o que demonstra a limitação da nodulação das plantas nesse ambiente. Ainda em relação à nodulação, é importante destacar que não foi observada interação significativa entre as cultivares e as estirpes inoculantes, o que mostra que as plantas foram capazes de nodular satisfatoriamente independentemente da estirpe.

Para o feijão-caupi, não existem informações conclusivas sobre o número mínimo de nódulos necessários para garantir bom desempenho da FBN, como é observado para a cultura da soja, para a qual se reconhece como suficientes 15 a 20 nódulos na coroa da raiz principal (Hungria \& Bohrer, 2000). Contudo, no presente trabalho, todas as cultivares tinham capacidade para formar nódulos suficientes para garantir a FBN, o que, no caso da cultivar BR 17 Gurguéia, corrobora estudos anteriores nos quais havia sido observada capacidade de nodulação maior em relação a outros genótipos de feijão-caupi de origem brasileira, nigeriana e norte-americana (Xavier et al., 2006).

Quanto à massa de matéria seca e $\mathrm{N}$ total na parte aérea, o tratamento com $\mathrm{N}$ apresentou valores superiores no campo. Nos tratamentos com inóculo, isso ocorreu em casa de vegetação, e os valores foram superiores em mais de $100 \%$ neste experimento (Tabela 2 ), o que demonstra que a menor nodulação das plantas no campo limitou a contribuição da FBN para o crescimento delas.

Em casa de vegetação, todas as cultivares apresentaram, na média geral, iguais massas de matéria seca (Tabela 3). No campo, entretanto, a cultivar BRS Guariba produziu mais massa de matéria seca que as cultivares BRS Mazagão e BR 17 Gurguéia, cujo valor foi também inferior ao da cultivar UFRR Grão Verde. Cabe destacar que as diferenças na massa de matéria seca da parte aérea entre as cultivares não podem ser atribuídas exclusivamente ao efeito das fontes de nitrogênio, porque a produção de biomassa tende a variar de acordo com o potencial genético da planta.

Quanto à interação das cultivares com fontes de nitrogênio (Tabela 3 ) em casa de vegetação, os maiores 
valores da massa de matéria seca foram observados para os tratamentos com inóculos, seguidos dos tratamentos nitrogenado e controle. A exceção ocorreu para a cultivar UFRR Grão Verde, cuja massa de matéria seca das plantas do tratamento com N, embora tenha sido maior, foi estatisticamente igual à do controle, o que indica que essa cultivar poderia ser menos eficiente na utilização do $\mathrm{N}$ mineral.

Para a variável $\mathrm{N}$ total, em casa de vegetação, os tratamentos com inóculos apresentaram valores maiores, seguidos do tratamento com $\mathrm{N}$ e do controle (Tabela 3 ), o que confirma a alta eficiência das estirpes em fixar o nitrogênio. Entretanto, também em casa de vegetação, foi observado maior acúmulo de $\mathrm{N}$ para a cultivar BR 17 Gurguéia, o que reflete a maior nodulação dessa cultivar, e menor para UFRR Grão Verde, para a qual não houve diferença entre o controle e o tratamento nitrogenado, provavelmente em razão da baixa resposta a este último tratamento.

Em relação à eficiência nodular, as cultivares não diferiram entre si (Tabela 3). Porém, entre as estirpes houve diferença significativa para a cultivar Pretinho Precoce 1, na qual BR 3262 apresentou eficiência superior à da estirpe BR 3267, o que indica que essa cultivar pode se beneficiar mais da FBN quando inoculada com BR 3262, pois houve maior acúmulo de $\mathrm{N}$ com esta estirpe. De forma

Tabela 2. Massa da matéria seca e $\mathrm{N}$ total da parte aérea de plantas de feijão-caupi com diferentes fontes de nitrogênio em de casa de vegetação e em campo, em Roraima ${ }^{(1)}$.

\begin{tabular}{lcccc}
\hline Tratamento & \multicolumn{2}{c}{ Massa da matéria seca (g por planta) } & & \multicolumn{2}{c}{ N total (mg por planta) } \\
\cline { 2 - 3 } & Casa de vegetação & Campo & Casa de vegetação \\
\hline Controle & $0,4 \mathrm{bD}$ & $3,5 \mathrm{aC}$ & $6,0 \mathrm{bC}$ \\
Nitrogenado & $6,5 \mathrm{bC}$ & $8,1 \mathrm{aA}$ & $113,6 \mathrm{aC}$ \\
BR 3267 & $10,9 \mathrm{aB}$ & $4,4 \mathrm{bBC}$ & $200,2 \mathrm{aA}$ \\
BR 3262 & $12,8 \mathrm{aA}$ & $4,9 \mathrm{bB}$ & $179,9 \mathrm{ba}$ \\
CV $(\%)$ & & & $383,6 \mathrm{aA}$ & $362,7 \mathrm{aA}$ \\
\hline
\end{tabular}

${ }^{(1)}$ Médias seguidas de letras iguais, minúsculas na linha e para uma mesma variável, e maiúsculas na mesma coluna e ambiente (casa de vegetação e campo), não diferem entre si pelo teste de Tukey, a $5 \%$ de probabilidade.

Tabela 3. Massa de matéria seca, $\mathrm{N}$ total da parte aérea e eficiência nodular de cultivares de feijão-caupi em casa de vegetação e em campo, em Roraima ${ }^{(1)}$.

\begin{tabular}{|c|c|c|c|c|c|c|}
\hline \multirow[t]{2}{*}{ Cultivar } & \multirow[t]{2}{*}{ Tratamento } & $\begin{array}{l}\text { Massa da matéria seca da } \\
\text { parte aérea (g por planta) }\end{array}$ & $\begin{array}{c}\mathrm{N} \text { total } \\
(\mathrm{mg} \text { por planta) }\end{array}$ & $\begin{array}{c}\text { Eficiência } \\
\text { nodular }\left(\mathrm{mg} \mathrm{mg}^{-1}\right)\end{array}$ & $\begin{array}{c}\text { Massa da matéria seca da parte } \\
\text { aérea ( } \mathrm{g} \text { por planta) }\end{array}$ & $\begin{array}{c}\mathrm{N} \text { total } \\
\text { (mg por planta) }\end{array}$ \\
\hline & & \multicolumn{3}{|c|}{ Casa de vegetação } & \multicolumn{2}{|l|}{ Campo } \\
\hline \multirow{4}{*}{ Pretinho Precoce 1} & Controle & $0,1 b$ & $1,4 \mathrm{c}$ & - & $3,5 b$ & $114,91 \mathrm{a}$ \\
\hline & Nitrogenado & $10,6 \mathrm{a}$ & $190,5 b$ & - & $6,2 \mathrm{a}$ & $177,99 \mathrm{a}$ \\
\hline & BR 3267 & $11,7 \mathrm{a}$ & $285,9 \mathrm{ab}$ & $0,8 \mathrm{~b}$ & $4,5 \mathrm{ab}$ & $161,31 \mathrm{a}$ \\
\hline & BR 3262 & $15,7 \mathrm{a}$ & $355,3 \mathrm{a}$ & $1,2 \mathrm{a}$ & $5,4 \mathrm{a}$ & $173,58 \mathrm{a}$ \\
\hline Média & & $9,5 \mathrm{~A}$ & $208,3 \mathrm{AB}$ & $1,0 \mathrm{~A}$ & 4,9ABC & $156,9 \mathrm{~A}$ \\
\hline \multirow{4}{*}{ UFRR Grão Verde } & Controle & $1,4 b$ & $20,9 \mathrm{~b}$ & - & $3,8 \mathrm{~b}$ & $115,81 b$ \\
\hline & Nitrogenado & $6,5 \mathrm{ab}$ & $103,0 \mathrm{~b}$ & - & $6,7 \mathrm{a}$ & $224,75 a$ \\
\hline & BR 3267 & $11,8 \mathrm{a}$ & $342,6 a$ & $0,9 \mathrm{a}$ & $4,7 \mathrm{~b}$ & $144,14 \mathrm{ab}$ \\
\hline & BR 3262 & $11,1 \mathrm{a}$ & $317,7 \mathrm{a}$ & $0,9 \mathrm{a}$ & $5,1 \mathrm{ab}$ & $156,11 \mathrm{ab}$ \\
\hline Média & & 7,7A & $196,1 \mathrm{~B}$ & $0,9 \mathrm{~A}$ & $5,3 \mathrm{AB}$ & $160,2 \mathrm{~A}$ \\
\hline \multirow{4}{*}{ BRS Mazagão } & Controle & $0,2 b$ & $2,4 \mathrm{c}$ & - & $3,1 \mathrm{~b}$ & $99,89 b$ \\
\hline & Nitrogenado & $7,4 a$ & $205,3 b$ & - & $6,9 \mathrm{a}$ & $227,39 a$ \\
\hline & BR 3267 & $10,5 \mathrm{a}$ & $360,7 \mathrm{a}$ & $0,8 \mathrm{a}$ & $4,1 b$ & $105,86 \mathrm{~b}$ \\
\hline & BR 3262 & $11,4 \mathrm{a}$ & $380,7 \mathrm{a}$ & $1,0 \mathrm{a}$ & $3,4 \mathrm{~b}$ & $139,04 \mathrm{~b}$ \\
\hline Média & & $7,4 \mathrm{~A}$ & $237,3 \mathrm{AB}$ & $0,9 \mathrm{~A}$ & $4,4 \mathrm{BC}$ & $143,0 \mathrm{~A}$ \\
\hline \multirow{4}{*}{ BR 17 Gurguéia } & Controle & $0,2 b$ & $3,8 \mathrm{c}$ & - & $3,0 \mathrm{a}$ & $87,82 \mathrm{a}$ \\
\hline & Nitrogenado & $8,2 \mathrm{a}$ & $205,4 b$ & - & $4,2 \mathrm{a}$ & $155,95 a$ \\
\hline & BR 3267 & $10,8 \mathrm{a}$ & $417,8 \mathrm{a}$ & $1,1 \mathrm{a}$ & $4,6 \mathrm{a}$ & $124,22 \mathrm{a}$ \\
\hline & BR 3262 & $11,6 \mathrm{a}$ & $449,4 \mathrm{a}$ & $1,3 \mathrm{a}$ & $4,8 \mathrm{a}$ & $171,52 \mathrm{a}$ \\
\hline Média & & 7,7A & $269,1 \mathrm{~A}$ & $1,2 \mathrm{~A}$ & $4,2 \mathrm{C}$ & $134,9 \mathrm{~A}$ \\
\hline \multirow{4}{*}{ BRS Guariba } & Controle & $0,1 \mathrm{c}$ & $1,4 \mathrm{c}$ & - & $4,14 \mathrm{c}$ & $143,66 a$ \\
\hline & Nitrogenado & $7,8 \mathrm{~b}$ & $195,4 b$ & - & $7,4 \mathrm{a}$ & $214,84 \mathrm{a}$ \\
\hline & BR 3267 & $9,5 \mathrm{ab}$ & $406,4 a$ & $1,0 \mathrm{a}$ & $4,3 \mathrm{~b}$ & $140,75 \mathrm{a}$ \\
\hline & BR 3262 & $14,1 \mathrm{a}$ & $414,8 \mathrm{a}$ & $1,3 \mathrm{a}$ & $5,7 \mathrm{ab}$ & $190,12 \mathrm{a}$ \\
\hline Média & & 7,9A & $254,5 \mathrm{AB}$ & $1,1 \mathrm{~A}$ & $5,4 \mathrm{~A}$ & $172,3 \mathrm{~A}$ \\
\hline $\mathrm{CV}(\%)$ & & 27,03 & 25,29 & 18,93 & 27,03 & 25,29 \\
\hline
\end{tabular}


semelhante, no Senegal, Fall et al. (2003) observaram interação entre cultivares de feijão-caupi e estirpes de rizóbio recomendadas naquele país em relação à redução de acetileno, que indica a atividade da nitrogenase e, indiretamente, a atividade nodular.

No campo, não foi observada diferença significativa entre as cultivares em relação ao $\mathrm{N}$ total (Tabela 3 ). Porém, entre as fontes de nitrogênio, o controle apresentou resultado inferior ao do tratamento nitrogenado dentro da cultivar UFRR Grão Verde, e os tratamentos com os inóculos apresentaram valores menores que o nitrogenado na cultivar BRS Mazagão. Os demais resultados não diferiram.

Na avaliação da massa de matéria seca e do $\mathrm{N}$ total da parte aérea do feijão-caupi no campo, a limitação na formação de nódulos restringiu o acúmulo de $\mathrm{N}$. Isso se confirma, pois, no tratamento nitrogenado, as cultivares acumularam $\mathrm{N}$ de forma semelhante nos dois experimentos (Tabela 2), enquanto as estirpes, apesar de terem proporcionado acúmulo de $\mathrm{N}$ maior que o do tratamento nitrogenado em casa de vegetação, proporcionaram valores inferiores no campo (Tabela 2). Dessa forma, embora tenham sido observadas diferenças entre as cultivares em relação às estirpes inoculantes, os maiores efeitos na FBN parecem estar relacionados com outros fatores que ocorrem no campo e que não foram considerados nas avaliações deste trabalho.

Em relação ao rendimento de grãos, não foi observada interação entre as cultivares e tratamentos. Contudo, a cultivar UFRR Grão Verde proporcionou rendimento maior que BR 17 Gurguéia, BRS Guariba e Pretinho Precoce 1; BRS Mazagão teve maior produtividade em relação a BR 17 Gurguéia (Tabela 4). Da mesma forma

Tabela 4. Rendimento de grãos de feijão-caupi em campo em Roraima ${ }^{(1)}$.

\begin{tabular}{lc}
\hline Tratamentos & \multicolumn{2}{c}{ Rendimento de grãos $\left(\mathrm{kg} \mathrm{ha}^{-1}\right)$} \\
\hline & \\
UFRR Grão Verde & $1.479,9 \mathrm{a}$ \\
BRS Mazagão & $1.401,0 \mathrm{ab}$ \\
Pretinho Precoce 1 & $1.259,8 \mathrm{bc}$ \\
BRS Guariba & $1.224,4 \mathrm{bc}$ \\
BR 17 Gurguéia & $1.098,9 \mathrm{c}$ \\
\hline & \\
Nitrogenado & Fontes de nitrogênio \\
BR 3262 & $1.455,0 \mathrm{a}$ \\
BR 3267 & $1.326,2 \mathrm{ab}$ \\
Controle & $1.271,5 \mathrm{~b}$ \\
CV(\%) & $1.118,6 \mathrm{c}$ \\
\hline
\end{tabular}

${ }^{(1)}$ Médias seguidas de letras iguais, em cultivares ou fontes de nitrogênio, não diferem entre si pelo teste de Tukey, a 5\% de probabilidade. que a massa de matéria seca, é preciso considerar que o potencial genético da planta, bem como a sua adaptabilidade às condições de campo, influenciaram no rendimento de grãos.

Entre as fontes de nitrogênio, maiores rendimentos de grãos foram obtidos com o tratamento nitrogenado e com inóculo da estirpe BR 3262, os quais apresentaram valores significativamente superiores aos do controle, enquanto a estirpe BR 3267, apesar de ter proporcionado rendimento igual ao da BR 3262, produziu menos que o nitrogenado (Tabela 4). Isto corrobora informações anteriores para a estirpe 3262 (Zilli et al., 2008) e mostra que, embora tenha havido restrição da nodulação das plantas no campo, a inoculação, especialmente com BR 3262, foi viável e capaz de substituir a adubação nitrogenada.

\section{Conclusões}

1. As cultivares BR 17 Gurguéia e Pretinho Precoce 1 apresentam maior e menor capacidade de nodulação, respectivamente.

2. As cultivares avaliadas apresentam alta eficiência nodular em casa de vegetação com ambas as estirpes de Bradyrhizobium, BR 3267 e BR 3262.

\section{Agradecimentos}

Aos Drs. Aloisio Alcantara Vilarinho e José Maria Arcanjo Alves, pelo fornecimento das sementes das cultivares de feijão-caupi.

\section{Referências}

CAMPO, R.J.; HUNGRIA, M. Protocolo para análise da qualidade e da eficiência agronômica de inoculantes, estirpes e outras tecnologias relacionadas ao processo de fixação biológica do nitrogênio em leguminosas. In: REUNIÃO DA REDE DE LABORATÓRIOS PARA RECOMENDAÇÃO, PADRONIZAÇÃO E DIFUSÃO DE TECNOLOGIA DE INOCULANTES DE INTERESSE AGRÍCOLA (RELARE), 13., 2006, Londrina. Anais. Londrina: Embrapa Soja, 2007. p.89-123. (Embrapa Soja. Documentos, 290).

CLAESSEN, M.E.C. (Org.). Manual de métodos de análise de solo. 2.ed. rev. atual. Rio de Janeiro: Embrapa-CNPS, 1997. 212p. (EMBRAPA-CNPS. Documentos, 1).

DELAVECHIA, C.; HAMPP, E.; FABRA, A.; CASTRO, S. Influence of $\mathrm{pH}$ and calcium on the growth, polysaccharide production and symbiotic association of Sinorhizobium meliloti SEMIA 116 with alfalfa roots. Biology and Fertility of Soils, v.38, p.110-114, 2003. 
FALL, L.; DIOUF, D.; FALL-NDIAYE, M.A.; BADIANE, F.A.; GUEYE, M. Genetic diversity in cowpea [Vigna unguiculata (L.) Walp.] varieties determined by ARA and RAPD techniques. African Journal of Biotechnology, v.2, p.48-50, 2003.

FRED, E.B.; WAKSMAN, S.A. Yeast extract-mannitol agar for laboratory manual of general microbiology. New York: McGraw Hill, 1928. 145p.

HARA, F.A. dos S.; OLIVEIRA, L.A. de. Características fisiológicas e ecológicas de isolados de rizóbios oriundos de solos ácidos e álicos de Presidente Figueiredo, Amazonas. Acta Amazônica, v.34, p.343-357, 2007.

HUNGRIA, M.; BOHRER, T.R.J. Variability of nodulation and dinitrogen fixation capacity among soybean cultivars. Biology and Fertility of Soils, v.31, p.45-52, 2000.

HUNGRIA, M.; CAMPO, R.J.; MENDES, I.C. A importância do processo de fixação biológica do nitrogênio para a cultura da soja: componente essencial para a competitividade do produto brasileiro. Londrina: Embrapa Soja, 2007. 80p. (Embrapa Soja. Documentos, 283).

LACERDA, A.M.; MOREIRA, F.M.S.; ANDRADE, M.J.B; SOARES, A.L.L. Yield and nodulation of cowpea inoculated with selected strains. Revista Ceres, v.51, p.67-82, 2004.

LIAO, C.F.H. Devarda's alloy method for total nitrogen determination. Soil Science Society of America Journal, v.45, p.852-855, 1981.

MARTINS, L.M.V.; XAVIER, G.R.; RANGEL, F.W.; RIBEIRO, J.R.A.; NEVES, M.C.P.; MORGADO, L.B.; RUMJANEK, N.G. Contribution of biological nitrogen fixation to cowpea: a strategy for improving grain yield in the semi-arid region of Brazil. Biology and Fertility of Soils, v.38, p.333-339, 2003.

MOREIRA, F.M.S. Bactérias fixadoras de nitrogênio que nodulam Leguminosae. In: MOREIRA, F.M.S.; SIQUEIRA, J.O.; BRUSSAARD, L. (Ed.). Biodiversidade do solo em ecossistemas brasileiros. Lavras: UFLA, 2008. p.621-680.

NEVES, M.C.P.; RUMJANEK, N.G. Diversity and adaptability of soybean and cowpea rhizobia in tropical soils. Soil Biology and Biochemistry, v.29, p.889-895, 1997.

NORRIS, D.O; DATE, R.A. Legume bacteriology. In: SHAM, N.H.; BRYAN, W.W. (Ed.). Tropical pasture research: principles and methods. Hurley: Commonwealth Bureau of Pastures and Field Crops, 1976. p.134-174. (Commonwealth Bureau of Pastures and Field Crops. Bulletin, 51).

RUMJANEK, N.G.; MARTINS, L.M.V.; XAVIER, G.R.; NEVES, M.C.P. Fixação biológica de nitrogênio. In: FREIRE FILHO, F.R.; ARAUJO LIMA, J.A.; SILVA, P.H.S.; RIBEIRO, V.Q. (Ed.).
Feijão-caupi: avanços tecnológicos. Brasília: Embrapa Informação Tecnológica, 2005. p.279-335.

SALVAGIOTTI, F.; CASSMAN, K.G.; SPECHT, J.E.; WALTERS D.T.; WEISS, A.; DOBERMANN, A. Nitrogen uptake, fixation and response to fertilizer $\mathrm{N}$ in soybeans: a review. Field Crops Research, v.108, p.1-13, 2008.

SANGINGA, N.; LYASSE, O.; SINGH, B.B. Phosphorus use efficiency and nitrogen balance of cowpea breeding lines in a low $\mathrm{P}$ soil of the derived savanna zone in West Africa. Plant and Soil, V.220, p.119-128, 2000.

SOARES, A.L. de L.; FERREIRA, P.A.A.; PEREIRA, J.P.A.R.; VALE, H.M.M. do; LIMA, A.S.; ANDRADE, M.J.B. de; MOREIRA, F.M. de S. Eficiência agronômica de rizóbios selecionados e diversidade de populações nativas nodulíferas em Perdões (MG): II - feijoeiro. Revista Brasileira de Ciência do Solo, v.30, p.803-811, 2006.

THIES, J.E.; BOHLOOL, B.B.; SINGLETON, P.W. Subgroups of cowpea miscellany: symbiotic specificity within Bradyrhizobium spp. for Vigna unguiculata, Phaseolus lunatus, Arachis hypogaea, and Macroptilium atropurpureum. Applied and Environmental Microbiology, v.57, p.1540-1545, 1991.

VINCENT, J.M. A manual for the practical study of root nodule bacteria. Oxford: Blackwell Scientific, 1970. 164p.

WATKIN, E.L.J.; O'HARA, G.W.; GLENN, A.R. Physiological responses to acid stress of an acid-soil tolerant and an acid-soil sensitive strain of Rhizobium leguminosarum biovar trifolii. Soil Biology and Biochemistry, v.35, p.621-624, 2003.

WILLEMS, A. The taxonomy of rhizobia: an overview. Plant and Soil, v.287, p.3-14, 2006.

XAVIER, G.R.; MARTINS, L.M.V.; RIBEIRO, J.R. de A.; RUMJANEK, N.G. Especificidade simbiótica entre rizóbios e acessos de feijão-caupi de diferentes nacionalidades. Caatinga, v.19, p.25-33, 2006.

ZHANG, W.T.; YANG, J.K.; YUAN, T.Y.; ZHOU, J.C. Genetic diversity and phylogeny of indigenous rhizobia from cowpea [Vigna unguiculata (L.) Walp.]. Biology and Fertility of Soils, v.44, p.201-210, 2007.

ZILLI, J.É.; VALICHESKI, R.R.; RUMJANEK, N.G.; SIMÕES-ARAÚJO, J.L.; FREIRE FILHO, F.R.; NEVES, M.C.P. Eficiência simbiótica de estirpes de Bradyrhizobium isoladas de solo do Cerrado em caupi. Pesquisa Agropecuária Brasileira, v.41, p.811-818, 2006.

ZILLI, J.É.; XAVIER, G.R.; RUMJANEK, N.G. BR 3262: nova estirpe de Bradyrhizobium para a inoculação de feijão-caupi em Roraima. Boa Vista: Embrapa Roraima, 2008. 7p. (Embrapa Roraima. Comunicado técnico, 10).

Recebido em 9 de fevereiro de 2009 e aprovado em 22 de agosto de 2009 